\title{
Molecular Orbital Studies on the Structure-Activity Relationships of Catechol O-Methyltransferase Inhibitors
}

\author{
Yasuko Shinagawa \\ Department of Physiology, Faculty of Medicine, Kyoto University, Kyoto 606, Japan \\ Received July 12, 1991 Accepted October 16, 1991
}

\begin{abstract}
Quantum chemical studies were applied to analyze the activities of catechol O-methyltransferase (COMT) inhibitors. Molecular orbital calculations of inhibitor molecules were made by semi-empirical molecular orbital calculations, $\mathrm{CNDO} / 2$ (complete neglect of differential overlap) methods. Regression analysis among theoretical reaction indices based on the frontier electron theory and COMT inhibitory activities were carried out. The COMT inhibitory actions of two series of inhibitors, a series of 1,5-substituted 3,4-dihydroxy benzenes and a series of substituted 3-hydroxy-4-methoxy benzenes, were investigated. The resulting regression equations contain two common reaction indices as regression variables: the electron density on the oxygen atom of the hydroxyl group and the super-delocalizability on the 5th carbon atom of the benzene ring. These two atomic positions are considered to play an important role in the interaction of these inhibitors with COMT. The hydroxyl of atomic position 3 is probably indispensable to the COMT inhibitory action by these inhibitors.
\end{abstract}

Catechol O-methyltransferase (COMT) plays an important role in the inactivation of catecholamines in vivo. This enzyme catalyzes the transfer of the methyl groups from $S$ adenosyl-L-methionine to phenolic hydroxyl groups of the catecholamines and a variety of other compounds with catechol structures (1). Recently, a number of COMT inhibitors have been synthesized and tested in expectation that they are useful for the treatment of diseases like Parkinson's disease $(2-4)$. Although a number of compounds have been tested for COMT activity and attempts have been made to design new potent inhibitors, the effect of substituents on the catechol ring has not been systematically evaluated. The activity of COMT inhibitors on COMT in vitro is ultimately ruled by the characteristic features of their quantum chemical structures and their molecular geometries. When the relationships between structure and activity are studied by correlation analyses for compounds with small structural variety, the rules developed from these observations can not be applied to compounds of various structures, and thcreby can not be useful for the development of new potent inhibitors.

In the present work, the correlation of semicmpirical molecular orbital (MO) parameters with the in vitro inhibitory activities of the COMT inhibitors on rat brain COMT (4) and rat liver COMT (5) was studied by multiple regression analysis. To determine more general key determinants of the COMT inhibitory activity and to elucidate the quantum chemical forces involved in the interactions at the active site of COMT, two series of inhibitors of the general structures I (5) and II (4) (Fig. 1) 
were investigated. It has been well-known that a variety of catechol derivatives can be inhibitors in vitro $(2-6)$ as well as substrates in vitro (1, 7-11) of COMT. Therefore, it is important to know which atomic position(s) of each inhibitor molecule is essential for the interaction of the inhibitor with COMT. Analyses of the structure-activity relationships by quantum chemical parameters can determine if the presence of two oxygen atoms attached to adjacent carbon atoms of the benzene ring is the only structural feature required for the interaction of inhibitor with COMT or whether the<smiles>[R]c1ccc(OC)c(O)c1</smiles>

1<smiles>[R]C1CC([R])([R])CC1([Y])[R]</smiles>

II
Fig. 1. Basic structures of monohydroxy-monomethoxy-benzene derivatives I and dihydroxy-benzene derivatives II. oxygen atom of the hydroxyl group has a different role from the other oxygen atom in these two series of inhibitors. These studies should also determine if the role of the hydroxyl group of monohydroxy-monomethoxybenzene derivatives corresponds to that of the 3-hydroxyl group or that of the 4-hydroxyl group of the substituted 3,4-dihydroxy benzene derivatives.

\section{METERIALS AND METHODS}

\section{Inhibitory activity of COMT}

The COMT inhibitory activities of two series of inhibitors $(4,5)$ were used in this regression analysis. One series is a group of 3hydroxy-4-methoxy benzene derivatives with one substituent instead of a bydrogen atom in the benzene ring. Their inhibitory activities on the COMT of rat liver are shown in Table 1 as percent inhibitions of the O-methylation of 3,4-dihydroxy-benzoic acid $\left(2 \times 10^{-3} \mathrm{M}\right)$; Inhibitors were each used at $2 \times 10^{4} \mathrm{M}$ (4).

Table 1. Percent inhibition of COMT ${ }^{*}$ and possible combinations of inhibitor molecules

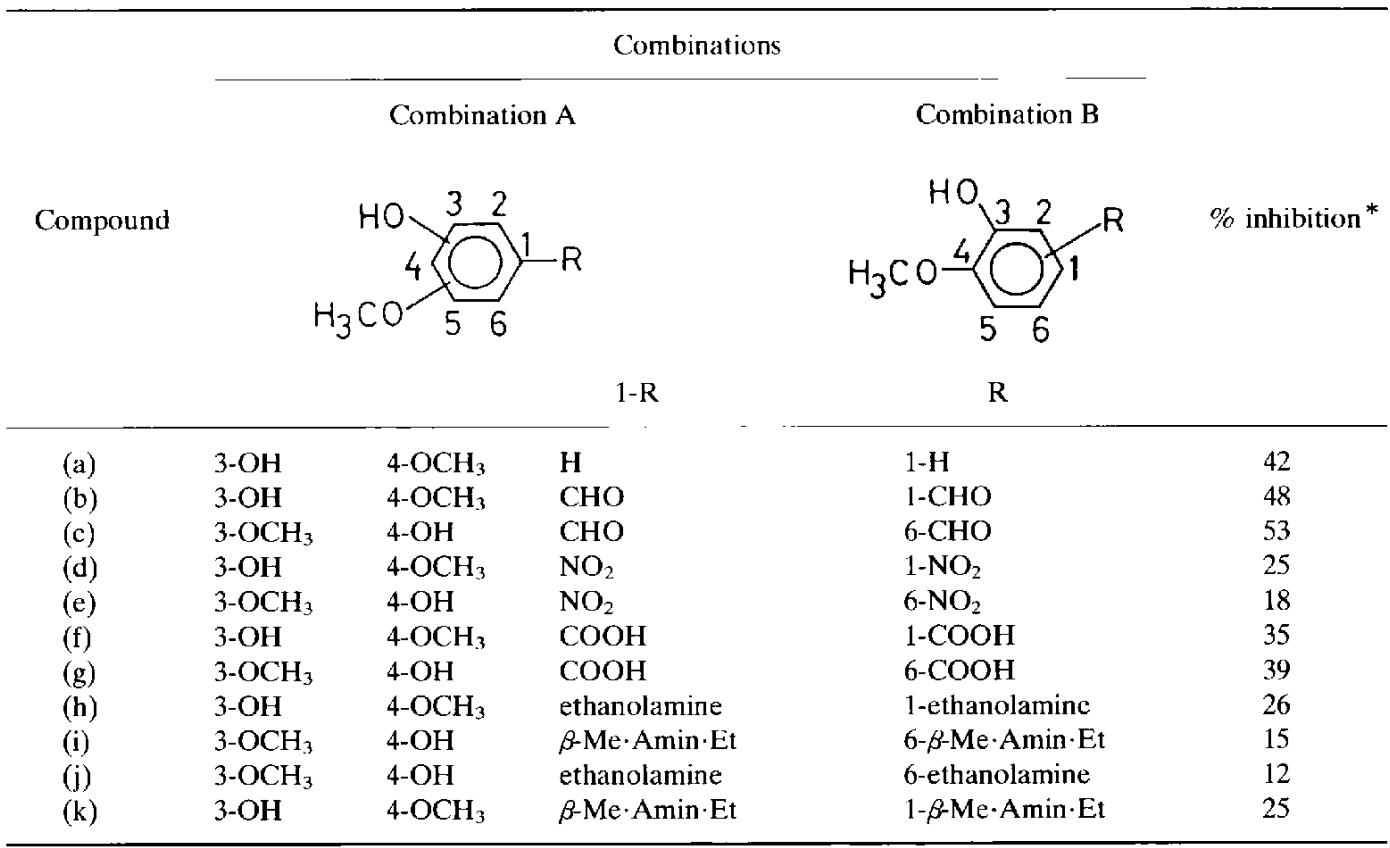

*: At the inhibitor concentration of $2 \times 10^{-3} \mathrm{M}$, ref. $5 ; \beta$-Me.Amin $\cdot \mathrm{Et}$ : $\beta$-methylaminoethanol. 
The other series of inhibitors is a group of $1,5-$ substituted 3,4-dihydroxy benzenes. Table 2 shows their inhibitory activities on the COMT of rat brain expressed by their $50 \%$ inhibitory concentrations $\left(\mathrm{IC}_{50} \mathrm{nM}\right)$ against the substrate 3,4-dihydroxy benzoic acid $(0.4 \mathrm{mM}$ substrate in a total reaction volume of $250 \mu 1(5)$ ).

\section{Molecular orbital calculations}

Molecualr geometries of COMT inhibitors were optimized (minimized energy) by semiempirical molecular orbital methods, $\mathrm{CNDO} / 2$ (complete neglect of differential overlap) methods $(12-15)$. Theoretical reaction indices $(16-21)$ by application of the frontier elcctron theory $(22-24)$ were calculated from MO parameters for the optimized geometries of the inhibitor molecules. The following indices were investigated: total energy; energy of
HOMO (the highest occupied molecular orbital); energy of LUMO (the lowest unoccupied molecular orbital); total electron density, $q_{r}$; net total charge, $Q_{r}$; frontier electron densities, $f_{r}^{(E)}, f_{r}^{(N)}, f_{r}^{(R)}$; super-delocalizabilities, $S_{r}{ }^{(E)}, S_{r}{ }^{(N)}, S_{r}{ }^{(R)}$; first super-delocalizabilities, $S_{r}{ }^{(E)}, S_{r}{ }^{(N)}$; socond super-delocalizabilities, $S^{\prime \prime}{ }_{r}(E), S{ }^{\prime}{ }_{r}(N)$; and atomic orbital gross population, $N_{r}$, where the subscript $r$ stands for an atom of the $r$ th position and superscripts $(E)$, $(N), \quad(R)$ indicate electrophilic (occupied level), nucleophilic (unoccupied level), and radical reactions, respectively. The total electron density $\left(q_{r}\right)$ is the summation of the electron densities of the occupied MO. The net total charge $\left(Q_{r}\right)$ is $n_{r}$ subtracted by $q_{r}$, and $n_{r}$ is the number of electrons brought to the molecular system by the atom $r$. The frontier electron density $\left(f_{r}^{(E)}\right)$ is the electron density

Table 2. COMT inhibitory activity of substituted catechol derivatives* and possible combinations of inhibitor molecules

\begin{tabular}{|c|c|c|c|c|c|}
\hline \multirow{4}{*}{ Compound } & \multicolumn{4}{|c|}{ Combinations } & \multirow{4}{*}{$\begin{array}{l}\mathrm{COMT}^{*} \\
\mathrm{IC}_{50} \mathrm{nM}\end{array}$} \\
\hline & & & Ry & & \\
\hline & \multicolumn{2}{|c|}{ Combination $\mathrm{C}^{*}$} & \multicolumn{2}{|c|}{ Combination D } & \\
\hline & $5-R_{x}$ & $1-R_{y}$ & $\mathrm{R}_{\mathrm{x}}$ & $\mathrm{R}_{\mathrm{y}}$ & \\
\hline (a) & $\mathrm{NO}_{2}$ & $\mathrm{Cl}$ & $2-\mathrm{NO}_{2}$ & $6-\mathrm{Cl}$ & 25 \\
\hline (b) & $\mathrm{NO}_{2}$ & $\mathrm{NO}_{2}$ & $5-\mathrm{NO}_{2}$ & $1-\mathrm{NO}_{2}$ & 12 \\
\hline (c) & $\mathrm{NO}_{2}$ & $\mathrm{COCH}_{3}$ & $5-\mathrm{NO}_{2}$ & $1-\mathrm{COCH}_{3}$ & 16 \\
\hline (d) & $\mathrm{NO}_{2}$ & $\mathrm{CH}: \mathrm{C}(\mathrm{Me}) \mathrm{Acet}$ & $2-\mathrm{NO}_{2}$ & 6-CH : C(Me)Acet & 12 \\
\hline (e) & $\mathrm{NO}_{2}$ & $\mathrm{CN}$ & $5-\mathrm{NO}_{2}$ & $1-\mathrm{CN}$ & 30 \\
\hline (f) & $\mathrm{CN}$ & $\mathrm{CHO}$ & $5-\mathrm{CN}$ & 1-CHO & 160 \\
\hline (g) & $\mathrm{NO}_{2}$ & $\mathrm{CHO}$ & $5-\mathrm{NO}_{2}$ & 1-CHO & 24 \\
\hline (h) & $\mathrm{CHO}$ & $\mathrm{CHO}$ & 5-CHO & 1-CHO & 160 \\
\hline (i) & $\mathrm{NO}_{2}$ & $\mathrm{COOH}$ & $5-\mathrm{NO}_{2}$ & $1-\mathrm{COOH}$ & 620 \\
\hline (j) & $\mathrm{CF}_{3}$ & $\mathrm{CHO}$ & $5-\mathrm{CF}_{3}$ & 1-CHO & 2300 \\
\hline (k) & $\mathrm{NO}_{2}$ & $\mathrm{CH}_{2} \mathrm{OH}$ & $5-\mathrm{NO}_{2}$ & $1-\mathrm{CH}_{2} \mathrm{OH}$ & 180 \\
\hline (1) & $\mathrm{SO}_{2} \mathrm{CH}_{3}$ & $\mathrm{CHO}$ & $5-\mathrm{SO}_{2} \mathrm{CH}_{3}$ & $1-\mathrm{CHO}$ & 20000 \\
\hline (m) & $\mathrm{H}$ & $\mathrm{COCH}\left(\mathrm{CH}_{3}\right)_{2}$ & $5-\mathrm{H}$ & $1-\mathrm{COCH}\left(\mathrm{CH}_{3}\right)_{2}$ & 6000 \\
\hline (n) & $\mathrm{Cl}$ & $\left(\mathrm{CH}_{2}\right)_{4} \mathrm{COOH}$ & $2-\mathrm{Cl}$ & $6-\left(\mathrm{CH}_{2}\right)_{4} \mathrm{COOH}$ & 8000 \\
\hline (o) & $\mathrm{NO}_{2}$ & $\mathrm{CH}: \mathrm{C}(\mathrm{CN})_{2}$ & $2-\mathrm{NO}_{2}$ & 6- $\mathrm{CH}: \mathrm{C}(\mathrm{CN})_{2}$ & 20 \\
\hline (p) & $\mathrm{NO}_{2}$ & $\left(\mathrm{CH}_{2}\right)_{4} \mathrm{COOH}$ & $2-\mathrm{NO}_{2}$ & $6-\left(\mathrm{CH}_{2}\right)_{4} \mathrm{COOH}$ & 90 \\
\hline
\end{tabular}

${ }^{*}$ : Ref. 4; (Me)Acet: $\left(\mathrm{CH}_{3}\right) \mathrm{COCH}_{3}$. 
of the HOMO. The super-delocalizability $\left(S_{r}^{(E)}\right)$ is the summation of the electron densities divided by the values of the energies of the occupied molecular orbitals. The first super-delocalizability $\left(S_{r}{ }_{r}{ }^{(E)}\right)$ is the $f_{r}{ }^{(F)}$ divided by the values of the energy of the HOMO; and the second super-delocalizability $\left(S^{\prime \prime}{ }_{r}^{(E)}\right)$ is the summation of the electron densitics divided the values of the energies of the HOMO and the second highest occupied MO. The atomic orbital gross population $\left(N_{r}\right)$ is $q_{r}$ plus the terms of the overlap integrals. The nucleophilic indices are defind by those of the unoccupied molecular orbitals. The iterative calculations were repeated until the electronic energy converges to $10^{-5}$ atomic units. The computer programs of the CNDO/INDO were provided by the Quantum Chemistry Program Exchange, Indiana University and modified by the author (25). MO calculations were performed by the supercomputer VP-400E and VP-2600 systems of the Kyoto University Data Processing Center, S-810 system of the Computer Center of the University of Tokyo and the $\mathrm{M}-680 \mathrm{H}$ system of the Institute for Molecular Science.

\section{Multiple regression analysis}

The tested regression equations were linear or parabolic equations as follows:

$$
\begin{aligned}
& f(x)=a+b x \\
& f\left(x, x^{2}\right)=a+b x+c x^{2} \\
& f(x, y)=a+b x+d y \\
& f(x, y, z)=a+b x+d y+e z
\end{aligned}
$$

Where $x, y, z$, are regression variables (theoretical reaction indices); $a, b, c$ are regression coefficients; and $f$ is the predicted biological activity. The atomic positions used in the regression analysis were 14 positions common to all the examined molecules (Fig. 2). The theoretical reaction indices used in the analysis were three energies (total energy, energy of HOMO, and energy of LUMO) and 182 indices ( 13 electronic indices per 14 atomic positions). These 185 theoretical indices were used as regression variables $x, y, z$ in equations $1,2,3$, and 4 . It is necessary in these re-

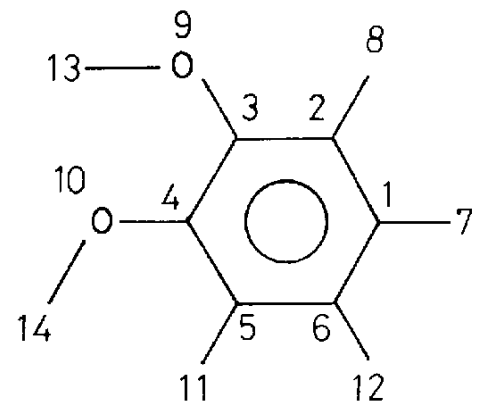

Fig. 2. Numbers of atomic positions that were used in the regression analysis.

gression analysis to know which atomic position of one inhibiter molecule corresponds to the atomic position of another inhibiter molecule with regards to COMT inhibitory action. Therefore, the correlations of electronic indices for the combinations shown in Table 1 (combinations A and B) and Table 2 (combinations $\mathrm{C}$ and $\mathrm{D}$ ) with COMT inhibitory activities were investigated in this work. Combination $\mathrm{A}$ in Table 1 and combination $\mathrm{C}$ in Table 2 are those of the original reports. In the original reports, these inhibitors were studied as the compounds with 3-O, 4-O, 1-substituted benzene structures (combination $\mathrm{A}$ in Table 1) or as compounds of $3-\mathrm{OH}, 4-\mathrm{OH}$, 1,5-substituted benzene structures (combination $C$ in Table 2). In spite of their apparent resemblance to epinephrine, the compounds shown in Tables 1 and 2 are quite different compounds from epinephrine. It is considered that the substituent attached to $\mathrm{C}_{1}$ of the benzene ring is not necessary for the geometrical recognition by COMT as shown by the COMT inhibitory activity of compound (a) in Table 1. Therefore, the possible combinations $B$ and D were also investigated in this work. Combination $B$ in Table 1 was based on the hypothesis that the hydroxyl group of the monohydroxymonomethoxy structure plays the most important role in the interaction of inhibitors with COMT and that the atomic positions of two ortho-oxygens attached to the benzene ring are needed for the geometrical recognition of inhibitor molecules by COMT, and that the 
substituent of the benzene ring modifies the electronic states of the inhibitors. Combination $D$ in Table 2 was based on the hypothesis that one of the two hydroxyls of the catechol structure plays the most important role in the interaction of inhibitors with COMT and that the selection of that hydroxyl is performed by the formal charge on the substituent at position 7 (Fig. 2). In this casc, the sign of the formal charge at position 7 is positive, and the positive formal charge at position 7 is larger than that at position 1 .

\section{RESULTS}

The optimized geomctries of 3-hydroxy-4methoxy benzene derivatives and 1,5-substituted 3,4-dihydroxy benzenes are shown in Figs. 3 and 4 . The maximum values of the correlation coefficients of COMT inhibitory activities with theoretical reaction indices for combinations $\mathrm{A}$ and $\mathrm{B}$ in Table 1 and for combinations $C$ and $D$ in Table 2 were 0.841 , $0.868,-0.846$, and -0.747 , respectively (Table 3). The theoretical indices in Table 4 are variables that gave the best twenty (with positive or negative sign) correlation coefficients for combinations $\mathrm{A}, \mathrm{B}, \mathrm{C}$, and $\mathrm{D}$ for monohydroxy-monomethoxy benzene derivatives as well as for 3,4-dihydroxy-benzene derivatives. Five indices: LUMO, $S_{I}^{(E)}, S_{3}{ }^{(E)}$, $S_{5}{ }^{(L)}$, and $S_{9}{ }^{(N)}$, were common to all the combinations. Therefore, the 25 theoretical reaction indices listed in Tables 3 and 4 had to be investigated in further regression analysis. Multiple regression analyses were performed with the theoretical indices listed in Tables 3 and 4 as regression variables.

The following regression equations gave the best correlation coefficients. The regression variables $S_{5}{ }^{(E)}$ and $q_{9}$ are common for equations 5 and 6 , and the signs of the regression coefficients in equation 5 coincide with those in equation 6 . Equation 5 is obtained by the analysis for combination $B$ and equation 6 , by the analysis for combination $\mathrm{C}$.

$$
\begin{aligned}
& f_{(p e r c e n t \text { inhibition })}=-12378.80-0.9299 S_{5}{ }^{(E)} \\
& ( \pm 67.49)( \pm 0.232) \\
& +1992.730 q_{9} \\
& ( \pm 9.052) \\
& (\mathrm{n}=11, \mathrm{r}=0.868) \\
& f_{\left(\ln \left(l / / C_{50}\right)\right)}=-1193.29-17.764 S_{5}{ }^{(E)} \\
& ( \pm 73.40)( \pm 11.170) \\
& +204.314 q_{9} \\
& ( \pm 2.929) \\
& (\mathrm{n}=16, \mathrm{r}=0.857)
\end{aligned}
$$

The numbers in parentheses are the $99 \%$ confidence limits. The total energics of optimized conformations of monohydroxy-monomethoxy benzene derivatives, the values of theoretical indices $q_{9}$ and $S_{5}{ }^{(E)}$ for combination $B$, and the observed and the predicted COMT inhibitory activities by regression equation 5 are listed in Table 5. The total energies of the optimized conformations of dihydroxy-benzene derivatives, the values of theoretical indices $q_{9}$ and $S_{5}{ }^{(E)}$ for combination $\mathrm{C}$, and the observed and the predicted COMT inhibitory activities by regression equation 6 are listed in Table 6 . The graph of predicted values vs. observed values by equations 5 and 6 are shown in Figs. 5 and 6 , respectively.

\section{DISCUSSION}

The aims of this work were to determine the regression equations that have common regression variables with the same signs of regression coefficients for two series of COMT inhibitors by the regression analysis of COMT inhibitory activities and quantum chemical parameters and to elucidate the quantum chemical interactions of inhibitors with COMT. Plural atomic positions are presumably necessary for the geometrical recognition of the inhibitor molecules by COMT. To determine the plural atomic positions that simultaneously interact with the binding site of COMT, it was necessary to use theoretical reaction indices that gave large correlation coefficients in the simple regression analyses as the regression variables. The correlation cocfficients with the 


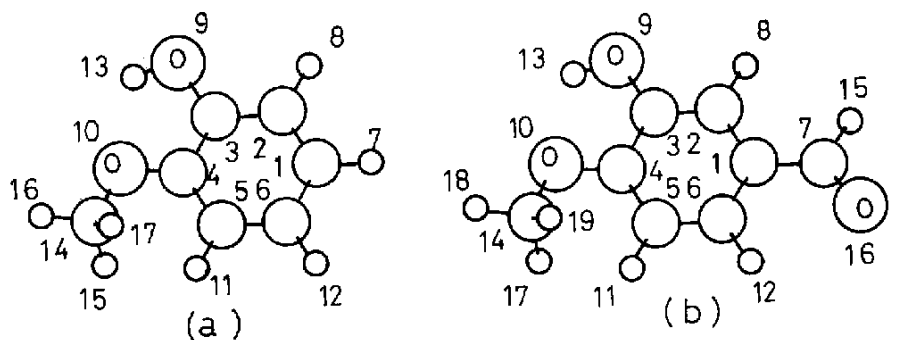

(a)
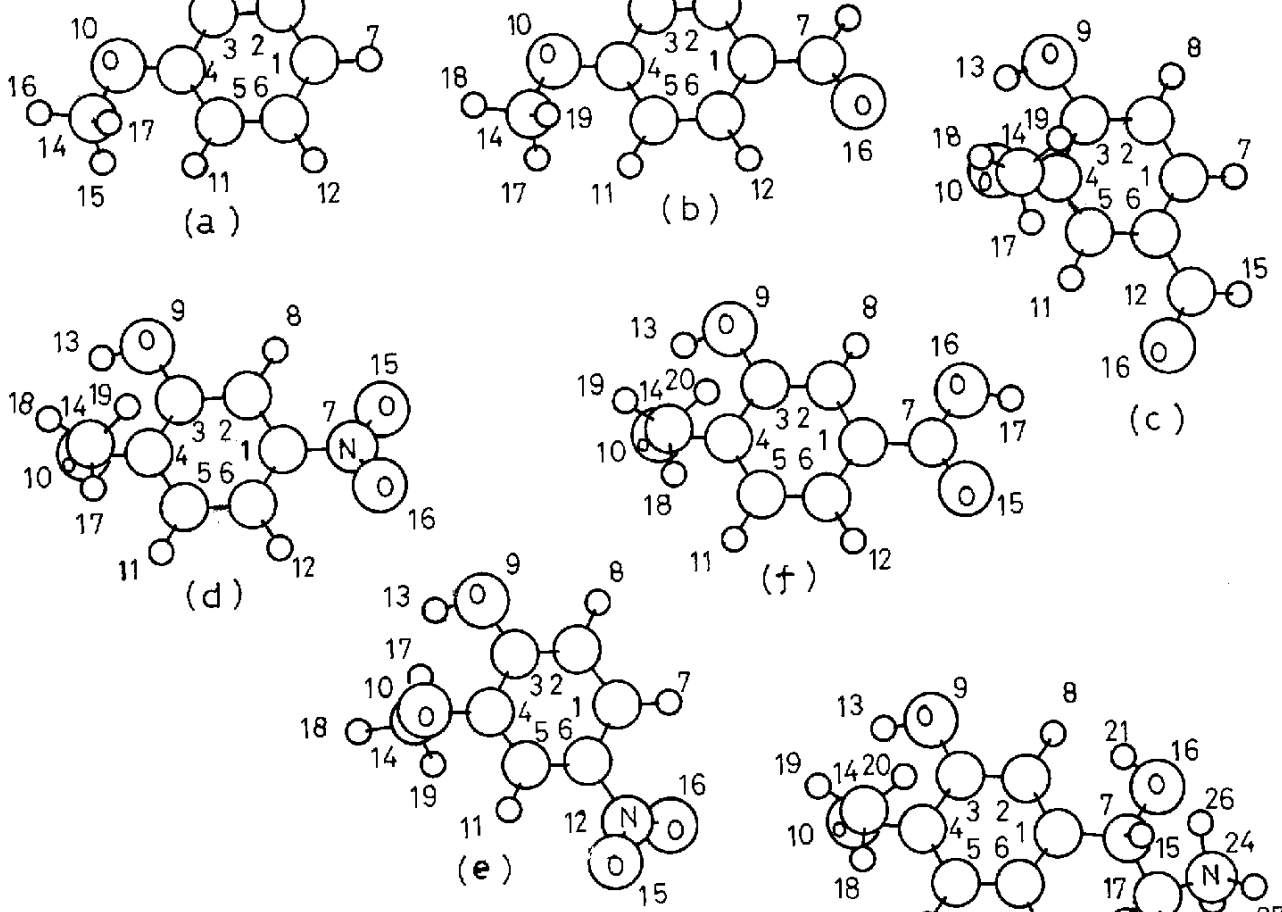
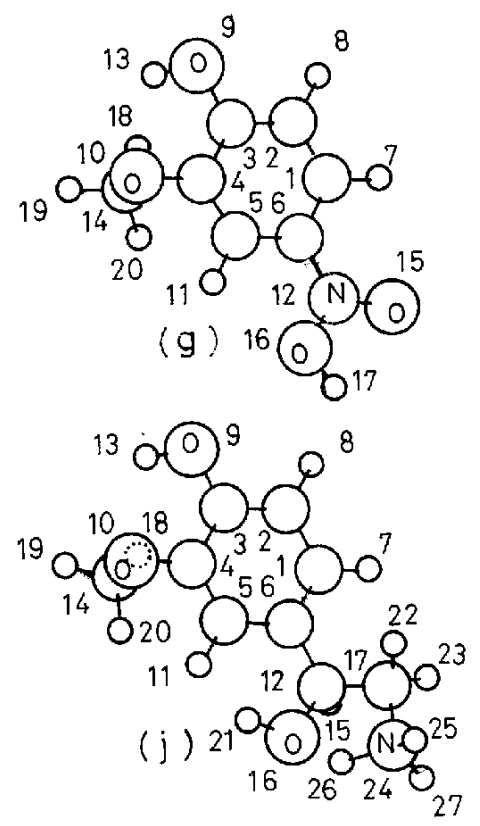

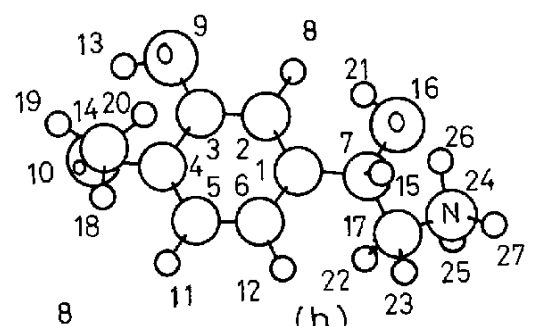

(h) 23

Fig. 3. The minimum energy conformations of monohydoxy-monomethoxy benzene derivatives. 

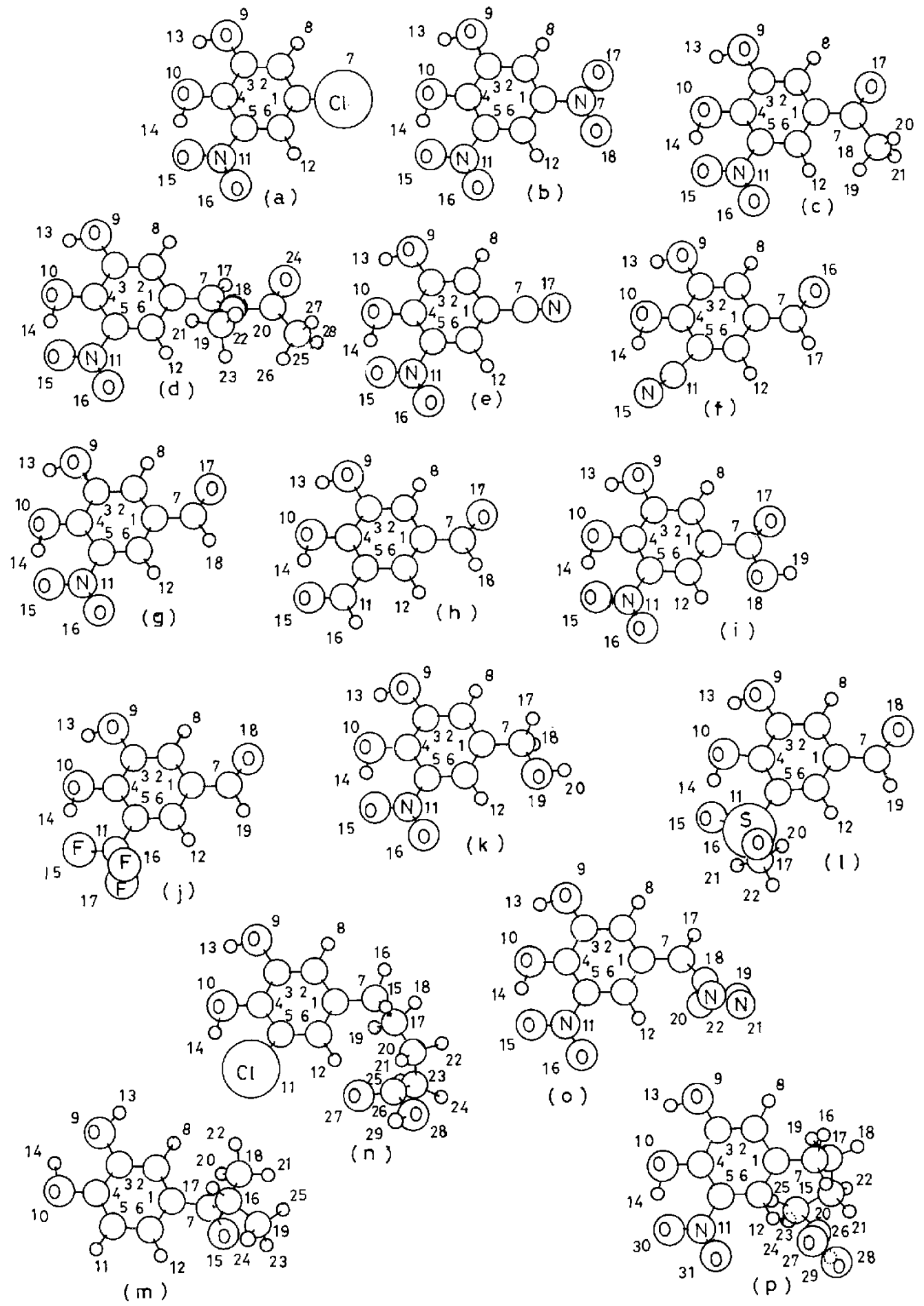

Fig. 4. The minimum energy conformations of dihydroxy-benzene derivatives. 
Table 3. Theoretical reaction indices that gave the correlation coefficients ${ }^{*}$ with the largest absolute values in the simple regression analyses, COMT inhibitory activities, and other related correlation coefficients

\begin{tabular}{|c|c|c|c|c|c|c|}
\hline \multirow[b]{2}{*}{$\begin{array}{l}\text { Biological } \\
\text { activity }\end{array}$} & \multirow[b]{2}{*}{ Combinations } & \multirow[b]{2}{*}{$\mathrm{n}$} & \multicolumn{4}{|c|}{$\begin{array}{l}\text { Correlation coefficients obtained for the following } \\
\text { theoretical indices: }\end{array}$} \\
\hline & & & $S_{12}(E)$ & $q_{9}$ & $S_{5}^{(E)}$ & $S_{3}^{(E)}$ \\
\hline$\%$ inhibition & $A$ & 11 & +0.841 & +0.702 & +0.728 & +0.743 \\
\hline$\%$ inhibition & B & 11 & -0.119 & +0.868 & +0.727 & +0.719 \\
\hline $\ln \left(1 / \mathrm{IC}_{50}\right)$ & $\mathrm{C}$ & 16 & -0.561 & -0.674 & -0.846 & -0.689 \\
\hline $\ln \left(1 / I C_{50}\right)$ & $\mathrm{D}$ & 16 & +0.237 & +0.348 & -0.610 & -0.747 \\
\hline
\end{tabular}

*: Diagonal values, $\mathrm{n}$ : Number of compounds.

Table 4. Theoretical indices that yielded the best twenty (with positive or negative sign) correlation coefficients for substituted-monomethoxy-monohydroxy benzene and substituted-dihydroxy benzenes and their correlation coefficients

\begin{tabular}{|c|c|c|c|c|c|c|c|c|c|}
\hline \multirow{2}{*}{$\begin{array}{l}\text { Theoretical } \\
\text { index }\end{array}$} & \multicolumn{4}{|c|}{ Combinations } & \multirow{2}{*}{$\begin{array}{l}\text { Theoretical } \\
\text { index }\end{array}$} & \multicolumn{4}{|c|}{ Combinations } \\
\hline & A & B & $\mathrm{C}$ & $\mathrm{D}$ & & A & B & $\mathrm{C}$ & D \\
\hline$S_{1}^{(E)}$ & 0.779 & 0.715 & -0.708 & -0.520 & $S_{4}^{(E)}$ & 0.717 & 0.779 & -0.552 & $-0.444^{*}$ \\
\hline$S_{3}^{(E)}$ & 0.743 & 0.719 & -0.689 & -0.747 & $S_{14}^{(E)}$ & $0.296^{*}$ & 0.752 & -0.642 & $-0.195^{*}$ \\
\hline$S_{5}(E)$ & 0.728 & 0.727 & -0.846 & -0.610 & $S_{0}^{(E)}$ & 0.746 & 0.737 & -0.634 & $0.095^{*}$ \\
\hline LUMO & 0.708 & 0.708 & -0.637 & -0.637 & $S_{33^{(E)}}$ & $-0.162^{*}$ & 0.720 & -0.617 & -0.512 \\
\hline$S_{0}{ }^{(N)}$ & -0.706 & -0.691 & 0.529 & 0.618 & $f_{1}^{(N)}$ & 0.685 & 0.701 & -0.553 & $-0.361^{*}$ \\
\hline$S_{I}^{(N)}$ & -0.694 & -0.710 & $0.448^{*}$ & 0.609 & $S_{14}^{(R)}$ & $0.038^{*}$ & -0.750 & 0.571 & $0.422^{*}$ \\
\hline$S_{6}^{(E)}$ & 0.758 & 0.822 & $-0.410^{*}$ & -0.515 & $S_{14}^{(N)}$ & $-0.024^{*}$ & -0.752 & 0.634 & $0.367^{*}$ \\
\hline$S_{6}^{(R)}$ & -0.712 & $-0.675^{*}$ & 0.522 & $0.356^{*}$ & $S_{2}^{(E)}$ & 0.739 & 0.760 & $-0.475^{*}$ & -0.650 \\
\hline$S_{6}(N)$ & -0.713 & $-0.677^{*}$ & 0.523 & $0.360^{*}$ & $S_{l i}^{(N)}$ & $-0.538^{*}$ & -0.698 & 0.597 & 0.701 \\
\hline$S_{8}(N)$ & -0.717 & $-0.638^{*}$ & 0.495 & $0.100^{*}$ & $S_{13}^{(R)}$ & $-0.494^{*}$ & -0.696 & 0.588 & 0.693 \\
\hline$q 9$ & 0.702 & 0.868 & -0.674 & 0.348 & $S_{\varphi}(R)$ & $-0.692^{*}$ & -0.679 & $0.476^{*}$ & 0.607 \\
\hline$S_{8}^{(E)}$ & 0.832 & 0.798 & -0.606 & $-0.179^{*}$ & $S_{I}{ }^{(H)}$ & $-0.691^{*}$ & -0.709 & $0.432^{*}$ & 0.594 \\
\hline
\end{tabular}

* An index that did not give one of the best twenty correlation coefficients.

largest absolute values in the simple regression analyses of the theoretical reaction indices with COMT inhibitory activites of the compounds for combinations $\mathrm{A}, \mathrm{B}, \mathrm{C}$ and $\mathrm{D}$ are shown as diagonal values in Table 3 . The theoretical indices that gave these correlation coefficients were $S_{12}{ }^{(E)}, q_{9}, S_{5}{ }^{(E)}$ and $S_{3}{ }^{(E)}$ as shown in Table 3. The off-diagonal values in Table 3 show the correlation coefficients among COMT inhibitory activities and these four indices for the remainder combinations.
However, the diagonal values of the correlation coefficients had the opposite signs in both group $\mathrm{A}$ or $\mathrm{B}$ and group $\mathrm{C}$ or D as shown in Table 3 . Therefore, regression equation 1 that employs a single variable was not sufficient for the consistent analysis of COMT inhibitory activities of these two different groups of inhibitors and quantum chemical reaction indices. No good correlation coefficients by parabolic regression as performed by equation 2 were found. The correlation coefficients 
Table 5. Values of theoretical reaction indices, the calculated and the observed ${ }^{*}$ COMT inhibitory activities of monomethoxy-monohydroxy-benzenes

\begin{tabular}{lccccc}
\hline Compound & $\begin{array}{c}\text { Total energy } \\
\text { (a.u.) }\end{array}$ & $q_{9}-b_{1}^{* *}$ & $S_{5}^{(E)}-b_{2}^{* * *}$ & $\begin{array}{c}\text { Calculated } \\
\text { values }\end{array}$ & $\begin{array}{c}\text { Observed } \\
\text { values }\end{array}$ \\
\hline (a) & -92.72016 & 0.00958 & 0.26720 & 50 & 42 \\
(b) & -188.16244 & 0.00734 & 0.18130 & 45 & 48 \\
(c) & -118.17401 & 0.00362 & 0.32113 & 38 & 53 \\
(d) & -140.56284 & -0.00105 & 0.18159 & 28 & 25 \\
(e) & -140.55992 & -0.00065 & 0.12153 & 29 & 18 \\
(f) & -136.66419 & 0.00312 & 0.32507 & 37 & 35 \\
(g) & -136.66118 & 0.00315 & 0.25473 & 37 & 39 \\
(h) & -141.57483 & -0.00398 & -0.41783 & 23 & 26 \\
(i) & -150.27311 & -0.00867 & -0.41007 & 14 & 15 \\
(j) & -141.57268 & -0.00934 & -0.43295 & 13 & 12 \\
(k) & -150.27540 & -0.00308 & -0.39168 & 25 & 25 \\
\hline
\end{tabular}

${ }^{*}$ : Ref. $5,{ }^{* *}: b_{1}=$ average of $q_{9}=6.22964,{ }^{* * *}: b_{2}=$ average of $S_{5}^{(E)}=4.83983$.

Table 6. Values of theoretical reaction indices, the calculated and the observed ${ }^{*}$ COMT inhibitory activities of dihydroxy-benzenes

\begin{tabular}{|c|c|c|c|c|c|}
\hline Compound & $\begin{array}{c}\text { Total energy } \\
\text { (a.u.) }\end{array}$ & $q_{6}-b_{3}^{* *}$ & $S_{5}^{(E)}-b_{4}^{* * *}$ & $\begin{array}{l}\text { Calculated } \\
\text { values }\end{array}$ & $\begin{array}{l}\text { Observed } \\
\text { values }\end{array}$ \\
\hline (a) & -147.30822 & -0.00259 & -0.10893 & -1.72366 & -3.22 \\
\hline (b) & -179.70889 & -0.00636 & -0.23607 & -2.95581 & -2.48 \\
\hline (c) & -166.02187 & -0.00111 & -0.09035 & -4.37912 & -2.77 \\
\hline (d) & -190.42111 & -0.00025 & -0.04829 & -3.78558 & -2.48 \\
\hline (e) & -149.66633 & -0.00125 & -0.11210 & -4.13690 & -3.40 \\
\hline (f) & -127.26915 & -0.00233 & -0.05014 & -4.89529 & -5.08 \\
\hline (g) & -157.32530 & -0.00171 & -0.10995 & -4.18277 & -3.18 \\
\hline (h) & -134.93713 & 0.00010 & 0.13542 & -6.90454 & -5.08 \\
\hline (i) & -175.81324 & -0.00291 & -0.10916 & -4.24728 & -6.43 \\
\hline (j) & -199.17414 & -0.00223 & -0.03651 & -5.88141 & -7.74 \\
\hline (k) & -159.04407 & 0.00192 & -0.04100 & -4.80319 & -5.19 \\
\hline (1) & -165.79721 & 0.00831 & 0.30190 & -8.42828 & -9.90 \\
\hline (m) & -135.62676 & 0.00484 & 0.28319 & -8.37485 & -8.70 \\
\hline (n) & -178.23131 & 0.00308 & 0.19801 & -9.68045 & -8.99 \\
\hline (o) & -183.33541 & -0.00049 & -0.08982 & -3.47314 & -3.00 \\
\hline (p) & -210.64774 & 0.00296 & 0.04072 & -4.28781 & -4.50 \\
\hline
\end{tabular}

${ }^{*}:$ Ref. $4,{ }^{* *}: b_{3}=$ average of $q_{9}=6.23262,{ }^{* * *}: b_{4}=$ average of $S_{5}^{(E)}=4.79961$.

obtained by equation 3 were hardly improved by equation 4 . Some of the correlation coefficients obtained by regression equations of the type exemplified by equation 4 were larger than those obtained by regression equations 5 and 6 after adjustment for the degrees of freedom. Some regression equations which gave those large correlation coefficients obtained by equation 4 contained the common variables for two series of COMT inhibitors. However, none of those regression equations yielded regreesion coefficients with coincident signs for both series of COMT inhibitors. The most excellent regression equations were found among the equation 3-type equations. The correlation coefficient by equation 7 for combination $D$ is 


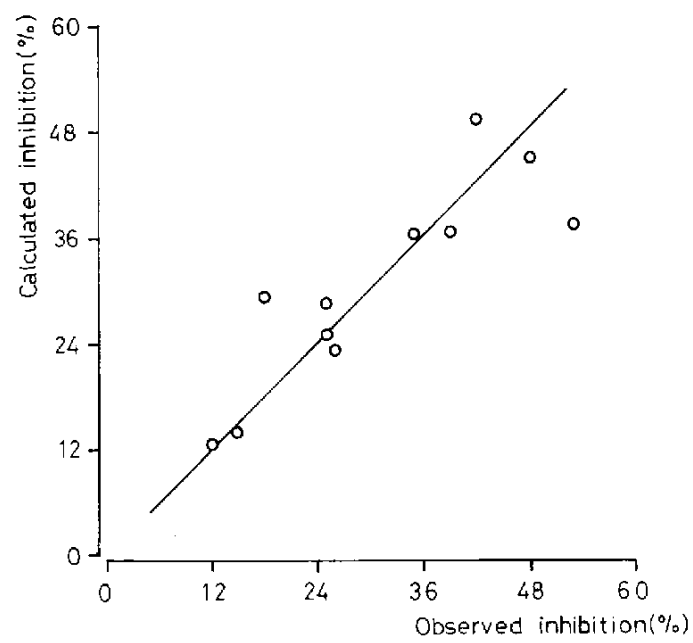

Fig. 5. Graphic display of the calculated vs, observed percent inhibition of COMT by monohydroxymonomethoxy-benzene derivatives.

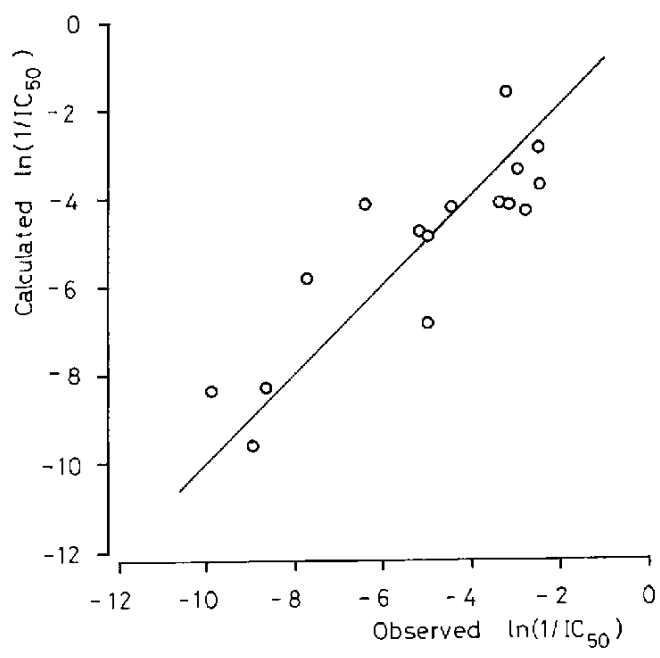

Fig. 6. Graphic display of the calculated vs. observed COMT inhibitory activity $\ln \left(1 / \mathrm{IC}_{50}\right)$ by dihydroxy-benzene derivatives.

slightly larger than that by equation 6 .

$$
\begin{aligned}
& f_{\left(\ln \left(1 / I C_{\sigma_{0}}\right)\right.}=-238.786-11.433 S_{5}{ }^{(E)} \\
& ( \pm 136.089)( \pm 10.252) \\
& +46.257 q_{9} \\
& ( \pm 13.541) \\
& (\mathrm{n}=16, \mathrm{r}=0.868)
\end{aligned}
$$

The parenthesized values are the $99 \%$ confidence limits, except for the $90 \%$ confidence limit of $S_{5}^{(E)}$. Therefore, the equation 7 is inferior to equation 6 because of the low significance of the coefficient of $S_{5}{ }^{(E)}$. Although all regression coefficients in equation 7 are significant within the $90 \%$ confidence limit, cquation 6 is more reasonable than equation 7 since all regression coefficients in equation 6 are significant within the $99 \%$ confidence limit.

The regression equation that gave the largest correlation coefficients in the analyses of COMT inhibitory activities by monohydroxy-monomethoxy benzene derivatives was equation 8 for combination $\mathrm{A}$.

$$
\begin{gathered}
f_{(\text {percent inhibition })}= \\
-15648.6+2523.4 q_{9} \\
-10.35 S_{14}^{(F)} \\
(\mathrm{n}=11, \mathrm{r}=0.946)
\end{gathered}
$$

However, this set of regression variables was not found among the excellent regression equations for any other combination of inhibitors. Therefore, equation 8 is not valid.

The inhibitors of combination A were considered to be $m$-O-methylated 1-substituted catechols or $p$-O-methylated 1-substituted catechols. Therefore, the regression analysis among the theoretical reaction indices and the COMT inhibitory activities by using combination A uses the working hypothesis that COMT recognizes three moieties: the moiety of the substituent and the moieties of the oxygen atoms at the meta and para positions of the substituent attached to the benzene ring of the inhibitor molecules. In combination $\mathrm{B}$, the inhibitors were considered to be the substituted ortho-methoxy phenol derivatives. Therefore, the regression analysis among the theoretical reaction indices and the COMT inhibitory activities of the using combination $B$ employs the hypothesis that COMT recognizes the moieties of the hydroxyl group and the methoxyl group of the substituted monohydroxy monomethoxy benzene derivatives and that COMT does not recognize the moiety of the substituent. Because combination $\mathrm{C}$ is a group of 1,5-substituted 3,4-dihydroxy ben- 
zene derivatives, COMT is expected to recognize: (a) the moieties of the 1 -substituent and two hydroxyls, (b) the moieties of the 5-substituent and two hydroxyls, or (c) the moieties of the two hydroxyls and the characteristics that distinguish one hydroxyl from the other hydroxyl. Combination D contains 3,4-dihydroxy benzene derivatives that have two substituents and whose atomic positions 1 and 7 satisfy the criteria that the sign of the formal charge at position 7 is positive and the formal charge at position 7 is larger than taht at position 1 .

The electrophilic (or nucleophilic) index suggests the interaction of the active site of these compounds with the electrophilic (or nucleophilic) center in the receptor. The radical index suggests a radical reaction. The frontier electrons play an orienting or guiding role in the configuration of the transition complex for the reaction. The super-delocalizability suggests that hyperconjugation plays an important role in decreasing the activation cncrgy in the reaction system.

Out of combinations A, B, C and D, combination $\mathrm{B}$ was selected as the preferable combination for monohydroxy-monomethoxy benzene derivatives and combination $\mathrm{C}$ was selected as the preferable combination for dihydroxybenzene derivatives. The common characteristic in the electronic states for all inhibitor molecules of combination $\mathrm{B}$ and $\mathrm{C}$ was that the value of the formal charge on atomic position 14 was larger than that on atomic position 13. The formal charges on atomic positions 13 and 14 presumably play an important role in the recognition of the geometries of these inhibitor molecules by COMT since the best regression equations were found in the analyses for combinations B and C. By analyzing COMT inhibitory activities by two series of inhibitors consistently, common regression variables for the two series were selected. These variables are the theoretical reaction indices $S_{5}{ }^{(E)}$ and $q_{9}$. The best regression equations to predict COMT inhibitory activities of monohydroxy-monomethoxy benzene derivatives and dihydroxy benzene derivatives are equations 5 and 6 , respectively.
Equations 5 and 6 contain theoretical reaction indices $S_{5}{ }^{(E)}$ and $q_{9}$ as the regression variables, and the signs of the regression coefficients in equation 5 are consistent with those in cquation 6 . The electron density of atomic position 9 (oxygen atom) and the super-delocalizability (16) of atomic position 5 (carbon atom) denote the possibility of a Coulombic interaction at $\mathrm{O}_{9}$ and the hyperconjugation at $\mathrm{C}_{5}$ to lower the activation energy to produce the intermediate state, respectively.

In conclusion, common factors to determine the COMT inhibitory actions of two series of inhibitors, monohydroxy-monomethoxy benzene derivatives and dihydroxy-benzene derivatives, were found: these determinants were $S_{5}{ }^{(E)}$ the super-delocalizability of the occupied molecular orbitals on atomic position 5 , and $q_{\varphi}$, the electron density at atomic position 9 . The reaction mechanism is considered to be as follows: COMT inhibitors approach COMT through a Coulombic interaction at atomic position 9 (oxygen atom), and then atomic position 5 (carbon atom) of the inhibitor interacts with an electrophilic site in COMT. It was noted that for the recognition of atomic positions by COMT, top priority is presumably given to the selection of atomic positions $\mathrm{O}_{9}$ and $\mathrm{O}_{10}$, and the substituent of the benzene ring modifies the electronic states of the inhibitor molecules since the preferable combination was combination $B$ in a series of monohydroxy-monomethoxy derivatives. The distinction between $O_{9}$ and $O_{10}$ in combinations $B$ and $C$ can be made by the values of the formal charges on atomic positions 13 and 14 , since the value of the formal charge on atomic position 14 was larger than that on atomic position 13. The hydroxyl on atomic position 3 is probably indispensable to the COMT inhibitory action by these inhibitors. This result suggests that two atomic positions, $\mathrm{O}_{9}$ and $\mathrm{C}_{5}$, of the inhibitor molecules interact with COMT.

\section{REFERENCES}

1 Axclrod, J. and Tomchick, R.: Enzymatic O- 
methylation of epinephrine and other catechols. J. Biol. Chem. 233, $702-705$ (1958)

2 Taskinen, J., Vidgren, J., Ovaska, M., Bäckström, R., Pippuri, A. and Nissinen, E.: QSAR and binding model for inhibition of rat liver catecholO-methyltransferase by 1,5-substituted-3,4-dihydroxybenzens. Quantitative Structure-Activity Relationships in Pharamocology, Chemistry and Biology 8, 210-213 (1989)

3 Männistö, P.T. and Kaakkola, S.: New selective COMT inhibitors: useful adjuncts for Parkinson's disease? TIPS 10, 54-56 (1989)

4 Bäckström, R., Honkanen, E., Pippuri, A., Kairisalo, P., Pystynen, J., Heinola, K. et al.: Synthesis of some novel potent and selective catechol O-methyltransferase inhibitors. J. Med. Chem. 32, $841-846$ (1989)

5 Nikodejevic, B., Senoh, S., Daly, W.J. and Creveling, C.R.: Catechol-O-methyltransferase. II. A new class of inhibitors of catechol-O-methyltransferase; 3,5-dihydroxy-4-methoxybenzoic acid and related compounds. J. Pharmacol. Exp. Ther. 174, 83 - $93(1970)$

6 Gugler, R. and Dengler, H.J.: Inhibition of human liver catechol-O-methyltransferase by flavonoids. Naunyn Schmiedebergs Arch. Pharmacol. 276, 223-233 (1973)

7 Axelrod, J.: Mcthylation reactions in the formation and metabolism of catecholamines and other biogenic amines. Pharmacol. Rev. 18, 95-113 (1966)

8 Katz, R. and Jacobson, A.E.: Chemical structureactivity correlation in the O-methylation of substituted catechols by catechol O-methyl transferase. Mol. Pharmacol. 8, 594 - 599 (1972)

9 Creveling, C.R., Morris, N., Shimizu, H., Ong. H.H. and Daly, J.: Catechol O-methyltransferase IV. Factors affecting $m$ - and $p$-methylation of substituted catechols. Mol. Pharmacol, 8, 398-409 (1972)

10 Borchardt, R.T.: Affinity labeling of catechol Omethyltransferase by the oxidation products of 6hydroxydopamine. Mol. Pharmacol. 11, 436-449 (1974)

11 Senoh, S., Tokuyama, Y. and Witkop, B.: The role of cations in non-enzymatic and enzymatic $\mathrm{O}$ methylations of catechol derivatives. J. Am. Chem. Soc. 84, 1719-1724 (1961)

12 Pople, J.A., Santry, D.P. and Segal, G.A.: Approximate self-consistent molecular orbital theory. I. Invariant procedures. J. Chem. Phys. 43, S129-S135 (1965)

13 Pople, J.A. and Segal, G.A.: Approximate selfconsistent molecular orbital theory. II. Calcula- tions with complete neglect of differential overlap. J. Chem. Phys. 43, S136-S151 (1965)

14 Pople, J.A. and Segal, G.A.: Approximate selfconsistent molecular orbital theory. III. CNDO results for AB2 and AB3 systems. J. Chem. Phys. 44, S289-S296 (1966)

15 Pople, J.A. and Segal, G.A.: Approximate selfconsistent molecular orbital theory. IV. Calculations on molecules including the elements sodium through chlorine. J. Chem. Phys. 47, 158-174 (1967)

16 Fukui, K., Yonezawa, T. and Nagata, C.: Theory of substitution in conjugated molecules. Bull. Chem. Soc. Japan 27, 423-427 (1954)

17 Fukui, K., Nagata, C. and Yonezawa, T.: Theoretical reactivity of addition in the "Frontier ElecIron Theory". Bull Chem. Soc. Japan 34, 230-232 (1961)

18 Fukui, K., Kato, H., Nagata, C. and Yonezawa, T.: A simple reactivity index for alternant hydrocarbons. Bull. Chem. Soc. Japan 34, 933-939 (1961)

19 Shinagawa, Y. and Shinagawa, Y.: A quantum pharmacological study on diuretics, xanthine, thiazide and triazine derivatives. Japan. J. Pharmacol. 23, 615-626 (1973)

20 Shinagawa, Y. and Shinagawa, Y.: Molecular orbital studies on $m$ - and $p$-methylation of substituted catechols by catechol O-methyltransferase. Int. J. Quantum Chem.: Quantum Biol. Symp. 5, $269-279$ (1978)

21 Shinagawa, Y. and Shinagawa, Y.: Regression analysis of enzyme reaction. O-Methylation of catechol derivatives by catechol-O-methyl transferase. Int. J. Quantum Chem. 18, 521-526 (1980)

22 Fukui, K., Yonezawa, T. and Shingu, H.: A molecular orbital theory of reactivity in aromatic hydrocarbons. J. Chem. Phys. 20, $722-725$ (1952)

23 Fukui, K., Yonezawa, T., Nagata, C. and Shingu, H.: Molccular orbital theory of orientation in aromatic, heteroaromatic, and other conjugated molecules. J. Chem. Phys. 22, 1433-1442 (1954)

24 Fukui, K., Morokuma, K., Yonezawa, T. and Nagata, $C$.: Charge transfer mechanism of reaction of conjugated molecules. J. Chem. Phys. 32, $1743-1747$ (1960)

25 Shinagawa, Y. and Shinagawa, Y.: The conformation of $o$-benzo-semiquinone radical and its assignment of the proton hyperfine coupling constants by using the INDO and the molecular geometry adjusting methods. Int. J. Quantum Chem. 29, $361-371(1986)$ 